\title{
ATTITUDES AND MOTIVATION OF MIDWIVES TO IMPROVE COMMUNICATIVE COMPETENCE
}

\author{
Zdravka Atanasova, Kremena Miteva \\ Department of Health Care, Medical Faculty, Trakia University
}

\begin{abstract}
INTRODUCTION: For the effective formation of knowledge, skills and competences, for their improvement and application in practice, the attitudes and motivation of the individual are essential.

AIM: The aim of the study is to investigate and analyze the attitudes and motivation of students, enrolled in the Midwife program at Trakia University, to develop communicative competence in the process of training or the inclination of practicing midwives in health institutions to improve their communicative competence.

MATERIALS AND METHODS: The size of the representative sample was 467 respondents, of which 73 were midwives working in the system of hospital obstetric care, 226 - patients, 155 - students enrolled in the Midwife program at the Trakia University, and 13 - lecturers. The results were processed with reliable mathematical and statistical methods and provided enough information to draw the necessary conclusions.

RESULTS AND CONCLUSION: It was determined that students from the Midwife program at Trakia University are highly critical of the level of their communication skills and have a positive attitude and motivation towards their improvement during the learning process. A significant part of practicing midwives are not critical of the level of communicative competence and have no motivation to improve in this direction.
\end{abstract}

Keywords: midwives, communicative competence, attitude, motivation, improvement

\section{INTRODUCTION}

The process of learning in a higher medical school aims to provide students with quality development of specific professional knowledge, skills, personal attitudes and behavior (3). The above-listed qualities shape in their totality the harmonious professional conduct of the midwife in a cognitive, emotional, social and emotional aspect (3).

Communicative competence is central to the professional conduct of health care specialists. It is measured by their ability to express and interpret

\author{
Address for correspondence: \\ Zdravka Atanasova \\ Department of Health Care, \\ Medical Faculty \\ Trakia University \\ 11 Armeyska St. \\ Stara Zagora \\ e-mail:zdravka.atanasova75@abv.bg
}

concepts, thoughts, feelings, facts and opinions, both orally and in a written form (listening, speaking, reading and writing), to communicate appropriately in all situations at work, and during their training (2).

Responsiveness allows midwives to carry out social contacts, social influence and coordination according to the ethical principles and professional qualifications. Communicative competence is a prerequisite for building effective styles of behavior and overcoming difficulties in typical and invariant situations in the health care environment.

The efficient formation of knowledge, skills and competencies, their improvement and application in practice to a large degree depend on the attitude and motivation of the individual.

Motivation is a process that activates, directs and maintains the behavior of an individual over time. An important aspect of motivation is obtain- 
ing a direct and intense relationship between targeted actions and their outcomes (1).

In a study in 2006 , T. Popov explored the motivation among higher medical school students in the country and noted that "the positive attitude is a prerequisite for positive learning outcomes" because "the motivated learner is more active, responsible and purposeful." (5).

Examining the factors, influencing positively on the motivation of the students for learning and opportunities to increase it, A. Andonova found that students in the programs: Nurse, Midwife, Social Activities and Health Care Management from the medical universities in Stara Zagora, Sofia and Plovdiv "are motivated to train in the chosen specialty. Over $2 / 3$ of all students have strong academic motivation" (1).

\section{AIM}

This scientific report aims to explore and analyze the attitudes and motivation of Midwife students in Trakia University for developing their communicative competence during the learning process, as well as of those, working in medical institutions, to improve their communicative competence.

\section{MATERIALS AND METHODS}

The following research methods are used in the process:

1. Questionnaire method - all the data were collected through an anonymous, direct, individual poll.
2. Documentary method - an analysis of training documentation for the Midwife program in Trakia University.

3. Mathematical and statistical methods - the data were processed using the package IBMSPSS Statistics Version 19 for Windows and Microsoft Office Excel 2007 (4).

The logical units monitored under the empirical survey are: midwives, Midwife program students, inpatients of obstetrics and gynecology departments, and university lecturers.

The technical units of observation are:

$\diamond$ Medical institutions for inpatient obstetric care (Hospitals: „Prof. Dr. Stoyan Kirkovich“- Stara Zagora; „NiaMed“ - Stara Zagora; „Trakia“ Stara Zagora; „Tota Venkova“ - Gabrovo)

$\diamond$ Trakia University - Stara Zagora.

Volume of the representative sample - 467 respondents. Among them:

$\diamond 73$ midwives working in the system of obstetrics and gynecology hospital care;

$\diamond 226$ patients (pregnant women, mothers and women with gynecological diseases);

$\diamond 155$ students studying in the Midwife program at Trakia University. (among them: 91 studying at the Faculty of Medicine - Stara Zagora and 76 studying at the branch of the Trakia University in Haskovo);

$\diamond 13$ university lecturers at Trakia University.

Data on the professional experience of the midwives, involved in the study: $27.4 \%$ of the midwives

Table 1. Distribution of students according to the year of study and the assessment

\begin{tabular}{|c|c|c|c|c|c|c|}
\hline \multirow{2}{*}{ Year of study } & & \multicolumn{4}{|c|}{ Assessment } & \multirow{2}{*}{ Total: } \\
\hline & & $\mathrm{C}$ & B & A & $\mathrm{D}$ & \\
\hline \multirow{2}{*}{ First } & number & 9 & 18 & 20 & 1 & 48 \\
\hline & $\%$ & $18.8 \%$ & $37.5 \%$ & $41.7 \%$ & $2.1 \%$ & $100.0 \%$ \\
\hline \multirow{2}{*}{ Second } & number & 0 & 10 & 26 & 10 & 46 \\
\hline & $\%$ & $0.0 \%$ & $21.7 \%$ & $56.5 \%$ & $21.7 \%$ & $100.0 \%$ \\
\hline \multirow{2}{*}{ Third } & number & 0 & 14 & 10 & 14 & 38 \\
\hline & $\%$ & $0.0 \%$ & $36.8 \%$ & $26.3 \%$ & $36.8 \%$ & $100.0 \%$ \\
\hline \multirow{2}{*}{ Fourth } & number & 1 & 7 & 12 & 3 & 23 \\
\hline & $\%$ & $4.3 \%$ & $30.4 \%$ & $52.2 \%$ & $13.0 \%$ & $100.0 \%$ \\
\hline \multirow{2}{*}{ Total: } & number & 10 & 49 & 68 & 28 & 155 \\
\hline & $\%$ & $6.5 \%$ & $31.6 \%$ & $43.9 \%$ & $18.1 \%$ & $100.0 \%$ \\
\hline
\end{tabular}


Zdravka Atanasova, Kremena Miteva

have professional experience of up to 10 years; $49.3 \%$ of the midwives have $11-20$ years of professional experience and $23.3 \%$ of them have professional experience of over 21 years. The results reveal that over $2 / 3$ of the midwives have considerable experience in the profession, which has qualitative advantages for this study. Nearly half of the midwives have a medical college education, which is directly related to the results of their professional experience and is determined by the reforms in midwife education over the past two decades.

The distribution of patients surveyed according to their age is: under 18 years old - $3.3 \% ; 19-35$ years old $-54.3 \%$; $36-45$ years old $-21.2 \%$; $46-60$ years old - $14.6 \%$ and over 61 years old $-6.6 \%$. The highest is the proportion of patients with secondary education $-59.6 \%$, followed by those with higher education $-33.1 \%$ and with primary education $-7.3 \%$.

Midwife program students account for $92 \%$ of the total number of students at the time of the study. The distribution of the surveyed students according to the year of study and the assessment is presented in Table 1.

As a proprotion, lecturers represent a very small percentage of the academic staff, providing education to students in the specialty. This is due to the raised criterion for inclusion - their involvement in the practical training /clinical practice and pregraduation practice/ of the students.

The distribution of lecturers according to their pedagogical experience is: $23.1 \%$ of them have up to 5 years of pedagogical experience; $38.5 \%$ have $6-10$ years of pedagogical experience; $30.7 \%$ of them have 11-20 years of pedagogical experience and $7.7 \%$ have over 21 years of pedagogical experience.

\section{RESULTS}

All the university lecturers and $89.7 \%$ of the students are convinced that the successful integration of midwives requires the development of special communication skills during their training. The differences in the responses of students according to the year of study and the assessment are not statistically significant $/ \mathrm{P}=0.680 /$.

Self-assessment of communicative competencies reveals the fact that $53.5 \%$ of the students think that they need additional knowledge in the field of communication; $18.7 \%$ cannot evaluate. About 43 students $/ 27.7 \%$ / think their knowledge is sufficient and they do not need additional education in communication skills. There were no statistically significant differences in the results according to the year of study $/ \mathrm{P}=0.680 /$ and assessment $/ \mathrm{P}=0.563 /$.

The question: "In your opinion, do health care students need additional knowledge in the sphere of communication?" received a resounding "yes" from $92.3 \%$ of the university lecturers.

$89.7 \%$ of the prospective midwives want to improve their communication skills. Table 2 presents the results of the surveyed students on the basis of their assessment.

The declared desire to improve their communication skills is the highest in third-year students /94.7\%/ and trainees $/ 91.3 \% /$. In the curriculum during the fourth year, Midwife program students conduct their internship, lasting no less than 1,600 astronomical hours. It is the final phase of training, which means it is not provided in other educational forms, ensuring the improvement of knowledge, skills and competences. In this aspect, the high percentage of students, who need additional knowledge in the field of communication is worrying. On one hand, they

Table 2. Willingness of students to improve their communication skills

\begin{tabular}{|c|c|c|c|c|c|c|}
\hline \multirow{2}{*}{\multicolumn{2}{|c|}{$\begin{array}{l}\text { Would you like to improve } \\
\text { your communication skills? }\end{array}$}} & \multicolumn{4}{|c|}{ Assessment } & \multirow{2}{*}{ Total: } \\
\hline & & C & B & A & $\mathrm{D}$ & \\
\hline \multirow{2}{*}{ Yes } & number & 9 & 43 & 60 & 27 & 139 \\
\hline & $\%$ & $90.0 \%$ & $87.8 \%$ & $88.2 \%$ & $96.4 \%$ & $89.7 \%$ \\
\hline \multirow{2}{*}{ No } & number & 1 & 6 & 8 & 1 & 16 \\
\hline & $\%$ & $10.0 \%$ & $12.2 \%$ & $11.8 \%$ & $3.6 \%$ & $10.3 \%$ \\
\hline \multirow{2}{*}{ Total: } & number & 10 & 49 & 68 & 28 & 155 \\
\hline & $\%$ & $100.0 \%$ & $100.0 \%$ & $100.0 \%$ & $100.0 \%$ & $100.0 \%$ \\
\hline
\end{tabular}

Scripta Scientifica Salutis Publicae, vol. 2, 2016, suppl. 1, pp. 57-61 
Attitudes and Motivation of Midwives to Improve Communicative Competence

Table 3. Opinion of midwives on the need to improve their communication skills - a professional internship

\begin{tabular}{|c|c|c|c|c|c|}
\hline \multirow{2}{*}{\multicolumn{2}{|c|}{$\begin{array}{l}\text { Do working midwives need further } \\
\text { improvement of their communication } \\
\text { skills? }\end{array}$}} & \multicolumn{3}{|c|}{ Internship divided into 3 groups } & \multirow[b]{2}{*}{ Total: } \\
\hline & & $11-20$ years & over 21 years & up to 10 years & \\
\hline \multirow{2}{*}{ Yes } & number & 12 & 22 & 8 & 42 \\
\hline & $\%$ & $60.0 \%$ & $61.1 \%$ & $47.1 \%$ & $57.5 \%$ \\
\hline \multirow{2}{*}{ No } & number & 4 & 9 & 4 & 17 \\
\hline & $\%$ & $20.0 \%$ & $25.0 \%$ & $23.5 \%$ & $23.3 \%$ \\
\hline \multirow{2}{*}{ I cannot decide } & number & 4 & 5 & 5 & 14 \\
\hline & $\%$ & $20.0 \%$ & $13.9 \%$ & $29.4 \%$ & $19.2 \%$ \\
\hline \multirow{2}{*}{ Total: } & number & 20 & 36 & 17 & 73 \\
\hline & $\%$ & $100.0 \%$ & $100.0 \%$ & $100.0 \%$ & $100.0 \%$ \\
\hline
\end{tabular}

Table 4. Opinion of midwives on the need to improve their communication skills-according to the EQD criteria

\begin{tabular}{|c|c|c|c|c|c|}
\hline \multirow{2}{*}{\multicolumn{2}{|c|}{$\begin{array}{l}\text { Do working midwives need further } \\
\text { improvement of their communica- } \\
\text { tion skills? }\end{array}$}} & \multicolumn{3}{|c|}{ EQD } & \multirow[b]{2}{*}{ Total: } \\
\hline & & $\begin{array}{l}\text { HCM Bachelor's } \\
\text { Degree / Master's } \\
\text { Degree }\end{array}$ & $\begin{array}{l}\text { College Medical } \\
\text { Education }\end{array}$ & $\begin{array}{l}\text { Midwife Bach- } \\
\text { elor's Degree }\end{array}$ & \\
\hline \multirow{2}{*}{ Yes } & number & 13 & 10 & 19 & 42 \\
\hline & $\%$ & $56.5 \%$ & $66.7 \%$ & $54.3 \%$ & $57.5 \%$ \\
\hline \multirow{2}{*}{ No } & number & 5 & 5 & 7 & 17 \\
\hline & $\%$ & $21.7 \%$ & $33.3 \%$ & $20.0 \%$ & $23.3 \%$ \\
\hline \multirow{2}{*}{ I cannot decide } & number & 5 & 0 & 9 & 14 \\
\hline & $\%$ & $21.7 \%$ & $0.0 \%$ & $25.7 \%$ & $19.2 \%$ \\
\hline \multirow{2}{*}{ Total: } & number & 23 & 15 & 35 & 73 \\
\hline & $\%$ & $100.0 \%$ & $100.0 \%$ & $100.0 \%$ & $100.0 \%$ \\
\hline
\end{tabular}

reveal a high level of criticism from the students in terms of acquired competences, but on the other hand there is an unmet need of obtaining knowledge in the studied area. The latter requires improving the organization of theoretical and practical training as well as ensuring effective implementation of relevant communication skills from the prospective health professionals.

The willingness of future midwives to improve their communicative competence can be seen in their choice of elective courses, focusing on professional medical communications. According to the curriculum of the Midwife program /in force since 2011/ students are able to choose training in "Psychosocial communication in nursing or midwife care" and "Pedagogy of communication". The proof of the willingness of students to improve their communica- tive competence is that $100 \%$ of them choose the first of these disciplines.

Self-assessment of the communicative competencies of the students from the Midwife program, who compare themselves with their colleagues, reveal the fact that $57.5 \%$ of midwives believe that workers in this sphere need further improvement. Of the opposite opinion are $-23.3 \%$. It is noteworthy that $1 / 5$ of respondents chose the answer "Cannot decide" or "I do not know." The breakdown of results according to the professional experience is presented in Table 3, and that according to the EQD criteria - in Table 4.

Most categorical in their self-assessment of the need for improving communicative competence are midwives who have upgraded their EQD /"yes" - 
Zdravka Atanasova, Kremena Miteva

66.7\%; "no" - 33.3\%/. Every fourth midwife with college medical education cannot assess herself.

For a comparison of the results of self-assessment of midwives we wanted the opinion of the subject of health care - pregnant women, mothers and women with gynecological diseases (Fig. 1).

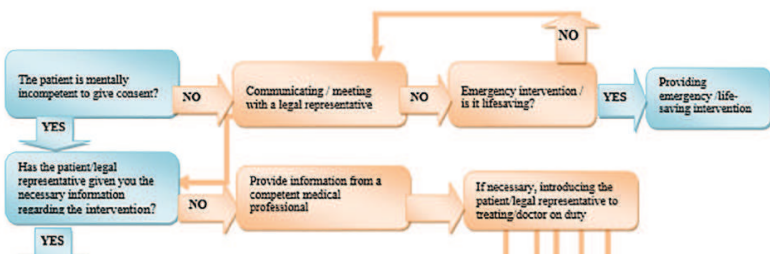

Figure 1. Opinion of the patients about the need to improve the communicative competence of midwives

Patients who firmly assess the need for midwives to improve their communicative competence have equal shares /85 - "yes" and 84 - "no"/. Each fourth pregnant, woman in labor or woman with a gynecological disease answers: "I cannot assess". The latter cannot be interpreted unambiguously. There is a possibility that the patients have refrained from assessing because of lack of competence about it, knowledge about communication, about the specifics of the communication models for health professionals, etc. It is accurate to recall that $2 / 3$ of the interviewees in the group do not have higher education. It does not allow the drawing of the conclusion that midwives do not need further improvement of their communication skills. On the other hand, the possibility is that this answer was indicated as a display of politeness by patients, who do not want to offend the midwives, who were currently caring for them.

The open-ended question "In what kind of form of training would you like to be included to improve the effectiveness of your communication?" was answered by $1 / 3 / 32.9 \% /$ of respondent midwives. Among them:

$\diamond 62.5 \% / 15$ midwives/ want to study a foreign language,

$\diamond 37.5 \%$ /9 midwives/ would participate in a course or a seminar to improve their communication skills. The majority of them (88.9\%) indicate that they would like this to happen at their workplace.

\section{CONCLUSION}

The analysis of the attitude and motivation of midwives /practicing and trainees in the program/ to improve their competence allowed us to draw the following conclusions:

$\diamond$ Students in the Midwife program at the Medical Faculty are highly critical of the level of their communicative competencies and have a positive attitude and motivation for their improvement during the learning process.

$\diamond$ Prospective midwives want to be active participants in the process of their professional formation. Placed in an educational environment on subject - subject basis, they accept positively the challenges of training in the field of health care. They show interest and activity regarding the educational disciplines that provide acquisition of practical professional knowledge, skills and competencies. This requires continuous development and implementation of effective organizational conditions and forms of building and improving the communicative competence of midwives in basic training.

$\diamond$ A significant proportion of practicing midwives are not critical of the level of their communicative competence and have no motivation to improve themselves in this direction.

\section{REFERENCES}

1. Andonova A. Training of Nurses. The Role of Motivation. 2013.

2. Atanasova Z, Kyuchukova S. The Student's motivation in Health Care to improve their communication skills. 9th International Balkans Education and Science Conference. Edirne. Turkey. 2014: 532-535.

3. Miteva Kr. The process of Training to Build Professional Competencies of Medical Specialists. Nursing magazine. 2011; 1: 49-50.

4. Peeva K. Biostatistics with IBM SPSS Statistics 19. Stara Zagora. Trakia University Press. 2013.

5. Popov T. The student being a Subject of the Learning Process. Medical Education. EX-Press Gabrovo. 2010. 